\title{
Deposition of Lipofuscin and Elastic Fibers in the Skin of the Senescence-Accelerated Mouse
}

\author{
Tomio OKada, ${ }^{1}$ Ritsuko Hayakawa, ${ }^{1}$ Kyoji Yoshino, ${ }^{2}$ \\ Sadaaki Komura, ${ }^{2}$ Kyoji Kondo, ${ }^{2}$ Nobuko OHISHI, ${ }^{2}$ \\ and Kunio YAGI ${ }^{2, *}$ \\ ${ }^{1}$ Division of Dermatology, Nagoya University Branch Hospital, Nagoya 461, Japan \\ ${ }^{2}$ Institute of Applied Biochemistry, Yagi Memorial Park, \\ Mitake, Gifu 505-01, Japan
}

(Received June 5, 1990)

\begin{abstract}
Summary In an animal model of aging, the accelerated senescenceprone (SAM-P/1) mouse, we found the deposition of lipofuscin and elastic fibers in the skin of 12-month-old animals of this strain. The deposition was most remarkable in the dorsal neck and head skin. Taking into account our previous data that the lipid peroxide level in the dorsal neck and head skin significantly increases prior to the appearance of the age-related signs in these areas of the skin, we propose that the increased lipid peroxides would cause the deposition of not only lipofuscin but also elastic fibers in the skin of SAM-P/1 mouse.
\end{abstract}

Key Words: lipofuscin, elastic fibers, skin, SAM, aging

Among many phenomena relating to aging, the most remarkable ones are the changes in the skin such as wrinkles, pigmentations etc.

We have been regarding lipid peroxides increased in the body as a direct cause of aging, and demonstrated, in our previous study [1] using the accelerated senescence-prone (SAM-P/1) mice, that lipid peroxides in the skin of these animals increase with age and that the increase occurs prior to the development of the age-related signs in the skin. We especially noted that the increase in lipid peroxide levels in the skin prior to the morphological changes was marked in the dorsal neck and head skin where the changes are most evident. Regarding histological observations on the skin of SAM-P/1 mice, systemic deposition of amyloid was already reported [2]. However, no other changes have ever been documented. The present investigation was undertaken to reveal microscopically

\footnotetext{
*To whom correspondence should be addressed.
} 
any possible change in their skin due presumably to the increased lipid peroxides.

\section{MATERIALS AND METHODS}

Animals. SAM-P/1 and the accelerated senescence-resistant (SAM-R/1) mice developed by Takeda et al. [3] were inbred and maintained in our institute under the following conditions: The temperature in the animal room was kept at $24^{\circ} \mathrm{C}$ with a 12-hour cycle of light emitted by an FL-40S.W/N lamp (Matsushita Electric Ind. Co., Ltd., Osaka). Light from this lamp contains only a small amount of ultraviolet ray A $\left(0.02 \mathrm{~mW} / \mathrm{cm}^{2}\right)$. The animals were given laboratory chow (CE-2, Clea Japan, Tokyo) and tap water ad libitum. Five male mice in each of 3 age groups (3-4,5-6, and 12-14 months old) examined were the same animals reported in our previous paper [1].

Skin tissues were excised from the regions of the head, dorsal neck, and hip. Specimens were fixed in buffered formalin and stained by the periodic acid shiff (PAS) reaction and the Schmorl method for lipofuscin, and by the Elastica-Van Gieson method for elastic fibers.

For electron microscopy, specimens were fixed in $2 \%$ paraformaldehyde with $2.5 \%$ glutaraldehyde in $0.1 \mathrm{M}$ cacodylate- $\mathrm{HCl}$ buffer $(\mathrm{pH} 7.4)$ and postfixed in $1 \%$ osmium tetroxide. After dehydration and embedding in Epon 812, sections were stained with tannic acid-uranyl acetate solution for $15 \mathrm{~min}$ and with Reynolds' lead citrate for $8 \mathrm{~min}$ [4]. They were then examined with a Hitachi H-600 electron microscope.

\section{RESULTS AND DISCUSSION}

\section{Deposition of lipofuscin in the skin}

Since lipofuscin has long been recognized to be increased with age in various tissues and organs, we investigated the possible deposition of this pigment in the skin of SAM-P/1 mice. In the skin of the animals of 12-14 months of age, deposits of lipofuscin granules were clearly observed by light microscopy. Figure 1 indicates light micrographs of dorsal neck skin of a 12-month-old male SAM-P/1 mouse. Upon staining with PAS, red granules were seen in the cytoplasm of fibroblasts in the dermis (Fig. 1A). After staining by the Schmorl method, dark-blue granules were observed (Fig. 1B). These observations indicate the deposition of a considerable amount of lipofuscin in the dermal fibroblasts of these animals.

Figure 2 is an electron micrograph of a dermal fibroblast in the dorsal neck skin of a 12-month-old SAM-P/1 mouse. Lipofuscin granules of various size and shape were observed in the lysosomes having a single membrane. Many small dense bodies and large lucent vacuoles were also seen there.

Table 1 summarizes the incidence of lipofuscin deposition in three regions of the skin of SAM-P/1 and SAM-R/1 mice of three different age categories. In both 

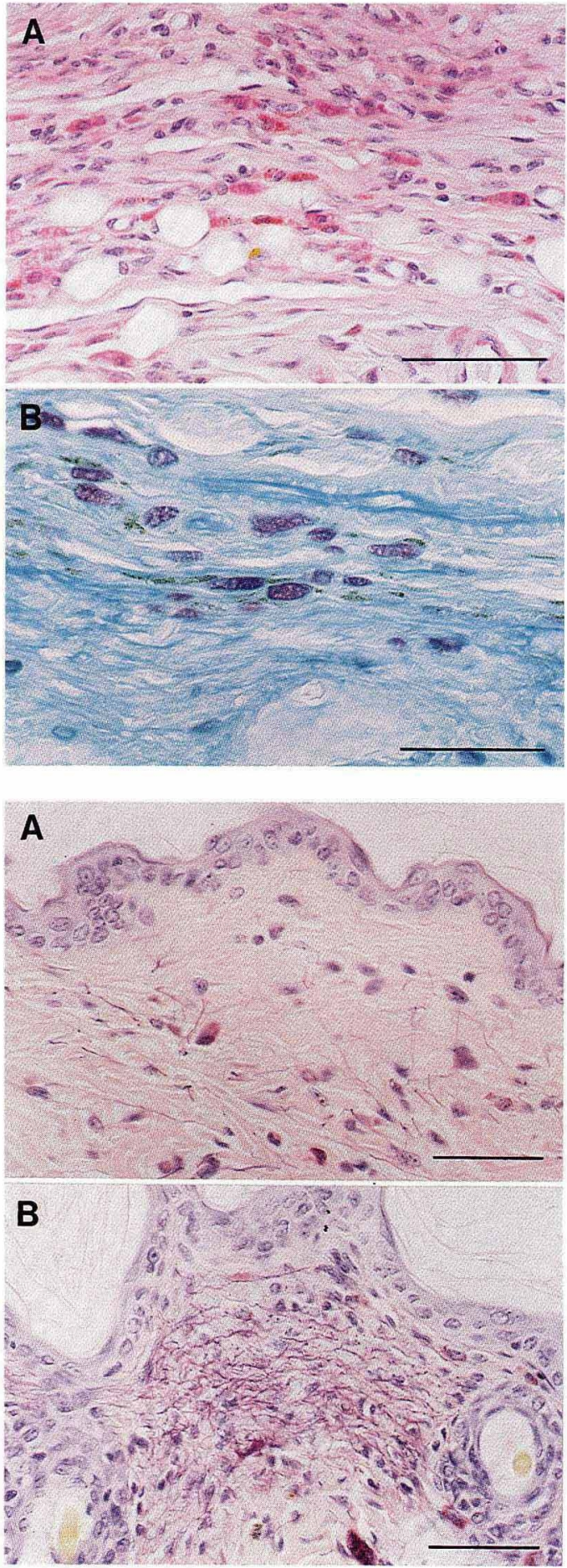

Fig. 1. Light micrographs of dorsal neck skin of a 12-month-old SAM$\mathrm{P} / 1$ mouse. Lipofuscin granules were stained by PAS reaction (A) or by the Schmorl method (B). Bar indicates $50 \mu \mathrm{m}$.

Fig. 3. Light micrographs of dorsal neck skin of 12-month-old SAM-P/ 1 and SAM-R/1 mice. A, SAM-R/ 1 mouse; B, SAM-P/1 mouse. Elastic fibers were stained by the Elastica-Van Gieson method. Bar indicates $50 \mu \mathrm{m}$.

Vol. 9, No. 3, 1990 
SAM-P/1 and SAM-R/1 mice of 3-4 and 5-6 months of age, lipofuscin deposition could not be observed in any region of the skin. At 12-14 months of age, however, lipofuscin granules were found in the skin of 4 out of 5 SAM-P/1 mice in the areas of the head and dorsal neck. In SAM-R/1 mice of 12-14 months of age, only one mouse had lipofuscin deposits in the head skin. No lipofuscin deposits were found in the skin of the hip region in either SAM-P/1 or SAM-R/1 mice.

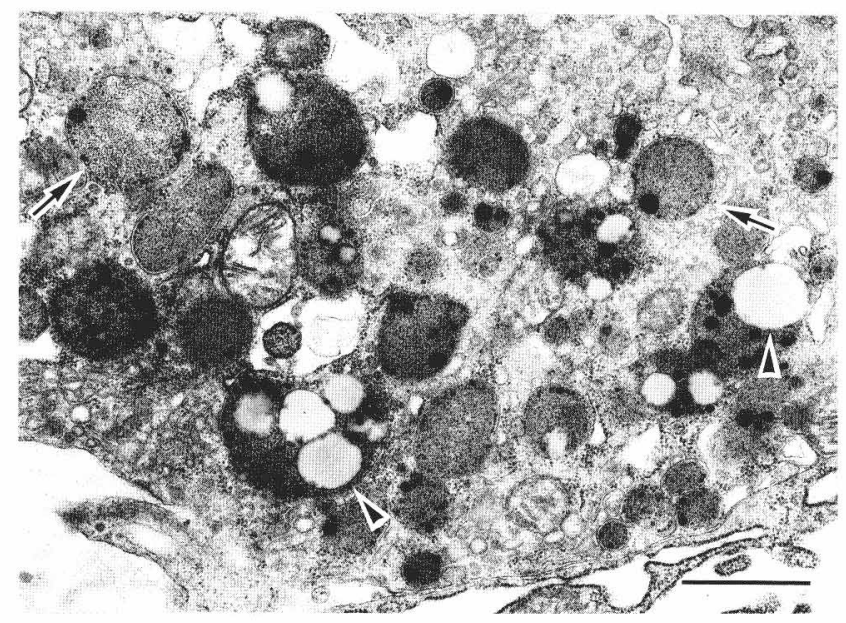

Fig. 2. Electron micrograph of a dermal fibroblast in dorsal neck skin of a 12-month-old SAM-P/1 mouse. Arrow indicates lipofuscin granules surrounded by a single membrane. Arrowhead indicates a lucent vacuole. Bar indicates $1 \mu \mathrm{m}$.

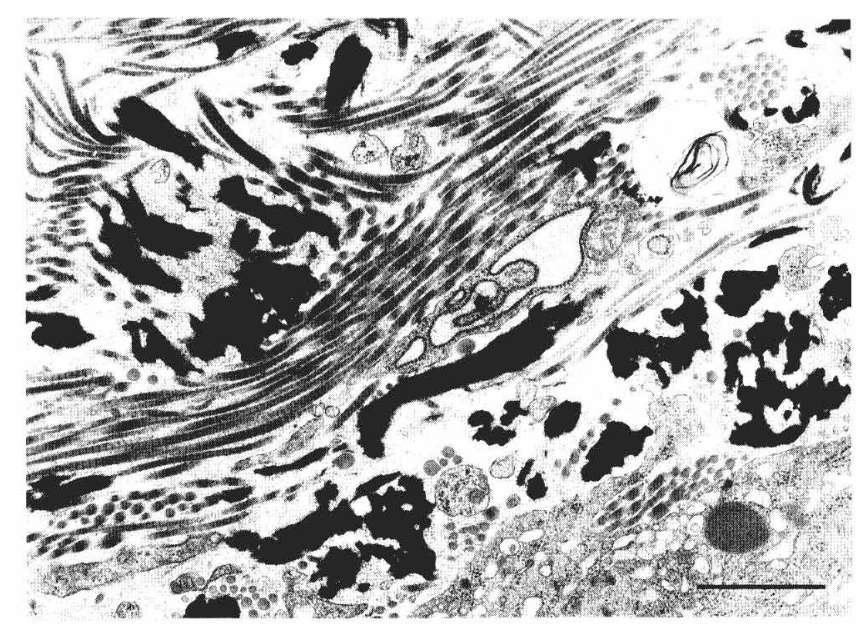

Fig. 4. Electron micrograph of elastic fibers in the dermis of dorsal neck skin of a 12-month-old SAM-P/1 mouse. Bar indicates $1 \mu \mathrm{m}$. 
Table 1. Deposition of lipofuscin in the skin of SAM-P/1 and SAM-R/1 mice of three different age categories.

\begin{tabular}{|c|c|c|c|c|c|c|c|}
\hline \multirow{2}{*}{$\begin{array}{c}\text { Age } \\
\text { (months) }\end{array}$} & \multirow{2}{*}{ SAM } & \multicolumn{2}{|c|}{ Head } & \multicolumn{2}{|c|}{ Dorsal neck } & \multicolumn{2}{|c|}{ Hip } \\
\hline & & - & + & - & + & - & + \\
\hline \multirow[t]{2}{*}{$3-4$} & $\mathrm{P} / 1$ & 5 & 0 & 5 & 0 & 5 & 0 \\
\hline & $\mathrm{R} / 1$ & 5 & 0 & 5 & 0 & 5 & 0 \\
\hline \multirow[t]{2}{*}{$5-6$} & $\mathrm{P} / 1$ & 5 & 0 & 5 & 0 & 5 & 0 \\
\hline & $\mathrm{R} / 1$ & 5 & 0 & 5 & 0 & 5 & 0 \\
\hline \multirow[t]{2}{*}{$12-14$} & $\mathrm{P} / 1$ & 1 & 4 & 1 & 4 & 5 & 0 \\
\hline & $\mathrm{R} / 1$ & 4 & 1 & 5 & 0 & 5 & 0 \\
\hline
\end{tabular}

Deposition of lipofuscin: - , negative; + , positive. Figure shows the number of mice.

Table 2. Deposition of elastic fibers in the skin of SAM-P/1 and SAM-R/1 mice of three different age categories.

\begin{tabular}{|c|c|c|c|c|c|c|c|c|c|c|}
\hline \multirow{2}{*}{$\begin{array}{c}\text { Age } \\
\text { (months) }\end{array}$} & \multirow{2}{*}{ SAM } & \multicolumn{3}{|c|}{ Head } & \multicolumn{3}{|c|}{ Dorsal neck } & \multicolumn{3}{|c|}{ Hip } \\
\hline & & - & + & ++ & - & + & ++ & - & + & ++ \\
\hline \multirow[t]{2}{*}{$3-4$} & $\mathrm{P} / 1$ & 5 & 0 & 0 & 5 & 0 & 0 & 5 & 0 & 0 \\
\hline & $\mathrm{R} / 1$ & 5 & 0 & 0 & 5 & 0 & 0 & 5 & 0 & 0 \\
\hline \multirow[t]{2}{*}{$5-6$} & $\mathrm{P} / 1$ & 5 & 0 & 0 & 5 & 0 & 0 & 5 & 0 & 0 \\
\hline & $\mathrm{R} / 1$ & 5 & 0 & 0 & 3 & 2 & 0 & 5 & 0 & 0 \\
\hline \multirow[t]{2}{*}{$12-14$} & $\mathrm{P} / 1$ & 1 & 2 & 2 & 1 & 1 & 3 & 5 & 0 & 0 \\
\hline & $\mathrm{R} / 1$ & 5 & 0 & 0 & 3 & 2 & 0 & 5 & 0 & 0 \\
\hline
\end{tabular}

Degree of elastic fiber deposition: - , negative; + , slight; ++ , marked. Figure shows the number of mice.

As reported in our previous paper [1], lipid peroxide levels in the skin of SAM-P/1 mice markedly increase at 3-4 months of age. In the present study, we found evidence of a remarkable deposition of lipofuscin in the 12-14-month-old group. These facts indicate that the increase in lipid peroxide levels in the skin obviously preceded the deposition of lipofuscin in the dermis. It is known that lipofuscin granules accumulate with advancement of age and that lipofuscin is formed by lipid peroxidation of polyunsaturated fatty acids of subcellular membranes [5]. The present observation that marked lipofuscin deposits were detected in the dermis of SAM-P/1 mice but not in that of SAM-R/1 mice strongly suggests the occurrence of lipid peroxidation damage in SAM-P/1 mice.

\section{Deposition of elastic fibers in the skin}

As another characteristic change in the skin of SAM-P/1 mice, we found deposits of elastic fibers in the connective tissue of the skin. Figure 3 shows light micrographs of the dorsal neck skin of 12-month-old SAM-P/1 and SAM-R/1 mice. In the skin of 12-month-old SAM-R/1 mice, histological features of the skin tissues showed a regular arrangement of thin elastic fibers. They are indistinguishable from those of the respective region of normal mice (data not shown). On the contrary, we observed many shrunken and tangled elastic fibers, which were 
stained dark-purple by the Elastica-Van Gieson method, in the middle and upper dermis of 12-month-old SAM-P/1 mice. These morphological features indicate the deposition of elastic fibers of decreased elasticity.

Elastic fibers in the dermis were examined by electron microscopy after staining with tannic acid. Figure 4 shows an electron micrograph of dermis in the dorsal neck skin of a 12-month-old SAM-P/1 mouse. Elastic fibers were seen to form amorphous matrices of high electron density. A number of microfibrils were distributed around the periphery of these amorphous matrices. These features again are evidence of an increased deposition of elastic fibers.

The incidence of SAM-P/1 and SAM-R/1 mice having different degrees of elastic fiber deposition is shown in Table 2. Among 5 SAM-P/1 mice in the $12-$ 14-month age category, 4 mice showed deposition of elastic fibers in their dorsal neck skin. Although 2 SAM-R/1 mice showed slight deposition of elastic fibers in both of 5-6-month age and 12-14-month age categories, the degree of elastic fiber deposition in SAM-P/1 mice was evidently more severe than that in SAM-R/1 mice. In the skin of the hip region, elastic fiber deposition was not evident in either strain of any age category.

It was reported that repeated ultraviolet radiation induced the deposition of elastic fibers in mice [6-9], rats [10], and dogs [11]. It was also reported that infrared radiation intensified such ultraviolet-induced dermal damage [12]. At present, the mechanism of deposition of elastic fibers is not clear. However, taking into account the fact that ultraviolet radiation increases free radicals and lipid peroxidation products $[13,14]$, we propose that lipid peroxides may play a role in the increased deposition of elastic fibers. In support of this view, we observed that the occurrence of elastic fiber deposition is more remarkable in SAM-P/1 mice than in SAM-R/1 mice. The deposition of elastic fibers in the dermis of SAM-P/1 mice was markedly observed in the skin of the dorsal neck and head, in which areas lipid peroxide levels were significantly increased, but not in the hip skin, where lipid peroxide level was lower than the levels in the dorsal neck and head skin.

These results reported in the present paper imply that deposition of both lipofuscin and elastic fibers in the skin is provoked by lipid peroxides increased in the skin. Deposition of lipofuscin would be partly responsible to the age-related pigmentation in the skin and that of elastic fibers to the decreased elasticity of the skin. Thus, age-related macroscopic changes of the skin, such as the pigmentation and wrinkles, would follow. Accordingly the signs observed in the skin with age would be caused, at least partly, by the increased lipid peroxides in situ.

\section{REFERENCES}

1. Komura, S., Yoshino, K., Kondo, K., and Yagi, K. (1988): Lipid peroxide levels in the skin of the senescence-accelerated mouse. J. Clin. Biochem. Nutr., 5, 255-260.

2. Higuchi, K., Matsumura, A., Honma, A., Takeshita, S., Hashimoto, K., Hosokawa, M., 
Yasuhira, K., and Takeda, T. (1983): Systemic senile amyloid in senescence-accelerated mice. A unique fibril protein demonstrated in tissues from various organs by the unlabeled immunoperoxidase method. Lab. Invest., 48, 231-240.

3. Takeda, T., Hosokawa, M., Takeshita, S., Irino, M., Higuchi, K., Matsushita, T., Tomita, Y., Yasuhira, K., Hamamoto, H., Shimizu, K., Ishii, M., and Yamamuro, T. (1981): A new murine model of accelerated senescence. Mech. Ageing Dev., 17, 183-194.

4. Kajikawa, K., Yamaguchi, T., Katsuda, S., and Miwa, A. (1975): An improved electron stain for elastic fibers using tannic acid. J. Electron Microscopy, 24, 287-289.

5. Tappel, A. L. (1973): Lipid peroxidation damage to cell components. Fed. Proc., 32, 18701874.

6. Sams, W.M., Jr., Smith, J.G., Jr., and Burk, P.G. (1965): The experimental production of elastosis with ultraviolet light. J. Invest. Dermatol., 43, 467-471.

7. Berger, H., Tsambaos, D., and Mahrle, G. (1980): Experimental elastosis induced by chronic ultraviolet exposure. Arch. Dermatol. Res., 269, 39-49.

8. Kligman, L.H., Akin, F.J., and Kligman, A.M. (1982): Prevention of ultraviolet damage to the dermis of hairless mice by sunscreen. J. Invest. Dermatol., 78, 181-189.

9. Hirose, R., and Kligman, L.H. (1988): An ultrastructural study of ultraviolet-induced elastic fiber damage in hairless mouse skin. J. Invest. Dermatol., 90, 697-702.

10. Nakamura, K., and Johnson, W.C. (1968): Ultraviolet light induced connective tissue changes in rat skin: A histopathologic and histochemical study. J. Invest. Dermatol., 51, 253-258.

11. Hargis, A.M., Thomassen, R.W., and Phemister, R.D. (1977): Chronic dermatosis and cutaneous squamous cell carcinoma in the beagle dog. Vet. Pathol., 14, 218-228.

12. Kligman, L.H. (1982): Intensification of ultraviolet-induced dermal damage by infrared radiation. Arch. Dermatol. Res., 272, 229-238.

13. Norins, A.L. (1962): Free radical formation in the skin following exposure to ultraviolet light. J. Invest. Dermatol., 39, 445-448.

14. Meffert, H., Diezel, W., and Sönnichsen, N. (1976): Stable lipid peroxidation products in human skin: Detection, ultraviolet light-induced increase, pathogenic importance. Experientia, 32, 1397-1398. 